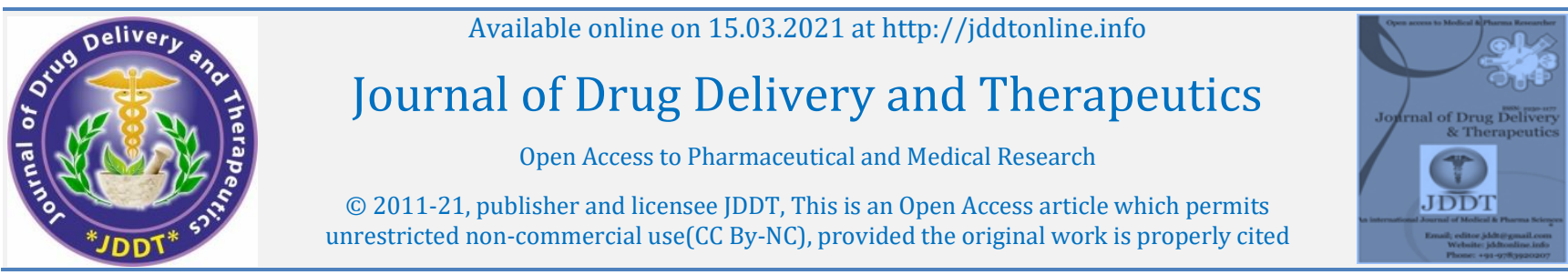

\title{
Evaluation of the Health Impact of the National Diabetes Program in Paraguay
}

\author{
Patricia Vera Rodríguez ${ }^{1}$, Zully Vera 1, Olga Maciel 1, Lupe Marin 2, Gladys Mabel Maidana 2, Gina Marin 2, \\ Gustavo H. Marin ${ }^{2 *}$ \\ ${ }^{1}$ Faculty of Chemical Science. National University of Asunción. San Lorenzo, Paraguay \\ ${ }^{2}$ National University of La Plata-CONICET, Argentina
}

\begin{tabular}{ll}
\hline Article Info: & \\
\hline & Article History: \\
& $\begin{array}{l}\text { Received 21 Jan 2021; } \\
\text { Review Completed 24 Feb } 2021 \\
\text { Accepted 02 March 2021; } \\
\text { Available online 15 March 2021 }\end{array}$ \\
\hline
\end{tabular}

Cite this article as:

Rodríguez PV, Vera Z, Maciel O, Marin L, Maidana GM, Marin G, Marin GH, Evaluation of the Health Impact of the National Diabetes Program in

Paraguay, Journal of Drug Delivery and

Therapeutics. 2021; 11(2):58-62

DOI: http://dx.doi.org/10.22270/jddt.v11i2.4597

*Address for Correspondence:

Prof. Dr. Gladys Mabel Maidana,

Faculty of Chemical Science. National University of Asunción Ruta Mcal. Estigarribia Km. 11,5 Campus

Universitario San Lorenzo, Paraguay

Prof. Dr. Gustavo H. Marin

National University of La Plata, Argentina

\section{Abstract}

The clinical evolution of a diabetic patient is linked to its compliance with nonpharmacological measures such as diet, physical activity, acquiring habits, medical controls and also with its pharmacological treatment.

In different Latin American countries such as the Republic of Paraguay, there are National Programs to provide free support and treatment to the diabetic population that mostly have vulnerable social conditions. However, the impact of these government policies is not routinely evaluated. In order to establish the achievements of a state diabetes program, the present study was carried out.

Methodology: This is a descriptive, cross-sectional study with an analytical stage.

Results: low adherence to non-pharmacological measures such as diet and physical activity was detected. A high percentage of patients were overweight $(38 \%)$ or obese $(46.5 \%)$. $75 \%$ of the population enrolled in this study did not comply with the program recommendations regarding the time and frequency of physical activities, nor they complied with the minimum 6 daily meals required. Only $37 \%$ of the patients had normal levels of glycated hemoglobin and $51.3 \%$ of them had pharmacological treatment adherence. Low compliance was observed in relation to regular medical examinations (which were under free coverage by the program) that are transposed in $22 \%$ of retinal studies and $60 \%$ in 24 -hour urine analysis for the early detection of complications such as retinopathy and nephropathy.

Conclusion: Despite the economic and logistical efforts carried out by State programs in order to care of people with diabetes mellitus, data showed a low adherence of patients to the proposed pharmacological and non-pharmacological measures. A personalized follow-up strategy is necessary to improve treatment adherence and to obtain better therapeutic results.

Keywords: Diabetes, adherence, treatment measures, National Program

\section{INTRODUCTION}

Diabetes Mellitus is a metabolic disease that is manifested by abnormal glucose levels in the blood ${ }^{1}$. Type 2 Diabetes Mellitus (DM2) is the one of the most common chronic disease in adults, and it occurs when the insulin secreted by the pancreas does not cover the needs of the patient ${ }^{2}$. It comprises a group of metabolic disorders characterized by chronic hyperglycemia, which is accompanied by secondary alterations in many organs, with high morbidity and mortality. ${ }^{3}$

The three major factors that determine the increase in the prevalence of diabetes in the world are a diet rich in simple carbohydrates (sugars, fat), a sedentary life and obesity. ${ }^{4-6}$

The chronic complications of Diabetes generally are developed due to poor illness control, which is related to elevate glucose levels and an increase in risk habits (sedentary lifestyle and improper diet). These elements are associated to complications for patient's health, such as a high risk of coronary artery disease, peripheral vascular disease, and stroke. ${ }^{7}$

In addition, type 2 diabetic patients are more likely to have hypertension and dyslipidemia. ${ }^{7}$

Despite the fact that pharmacological treatments with antidiabetic agents have grown exponentially in the last decades, it should be noted that the first-line treatment must be non-pharmacological approaches including diet modification, weight control and regular exercise.

The biggest problem for the health system is the lack of patient's adherence to recommendations referred to lifestyle changes or to treatment compliance ${ }^{7}$. 
Patient's adherence rates for non-pharmacological approaches in chronic diseases are usually less than $50 \%$, although they may vary from country to country 8,9 . Hence, it is important to have local data in each region, in order to conduct the right health policies.

The World Health Organization (WHO) ensures that "noncompliance with treatment is the main cause of not obtaining all the benefits that medical treatment can provide to patients"10, and that is why it is reflected in a true public health problem, becomes a barrier in disease prevention processes and plays a crucial role in the development of morbidity and mortality and 10 .

The National Diabetes Program of the Ministry of Public Health and Social Welfare of the Republic of Paraguay provides adequate tools for the daily management of the disease in the diabetic population, however its real health impact is still ignored ${ }^{11}$. In order to estimate the benefit of the National Diabetes program in terms of health indicators, the present work was performed.

\section{METHODOLOGY}

Type of Study: It is a descriptive, observational, crosssectional study.

Study Universe: Type 2 diabetic patients benefiting from the National Diabetes Program.

Sample: A sample of program beneficiaries in the capital city of Asunción over 40 years old was obtained.

Data Collection Tool: data was extracted from specific questionnaire and from clinical record of patients from the National Diabetes Program

Variables: sex, age, years of disease, HBA1C, cholesterol, triglycerides, weight, height, body mass index, fundus, 24hour urine test, pharmacological treatment, nonpharmacological measures; degree of compliance with nonpharmacological/pharmacological treatment, and participation in activities of the National Program were the main variables explored.

A total of 482 patients were enrolled in the study; $73 \%$ were women and $27 \%$ men. Their mean age was $64.96 \pm 10.3$ years.

\section{RESULTS AND DISCUSSION}

Based on the statistical analysis of the questionnaire data, and the data extracted from the clinical history, the results were classified in each of the treatment pillars established.

The results on eating habits in relation to the meals that the patients reported in study questionnaire showed that breakfast, lunch and dinner are the most respected intakes (Fig. 1). The $100 \%$ of patients complied with breakfast and lunch, and $98.8 \%$ with dinner. Slightly lower percentages were observed in the mid-morning snack (89\%), and in the afternoon snack (91.5\%); while only $50 \%$ of the patients had accomplished with the night meal. Most of the patients reported that the did know how many times a day they should eat to comply with the Program's meal plan, however, most of them eat less that the minimum of meals recommended (fig. 1).

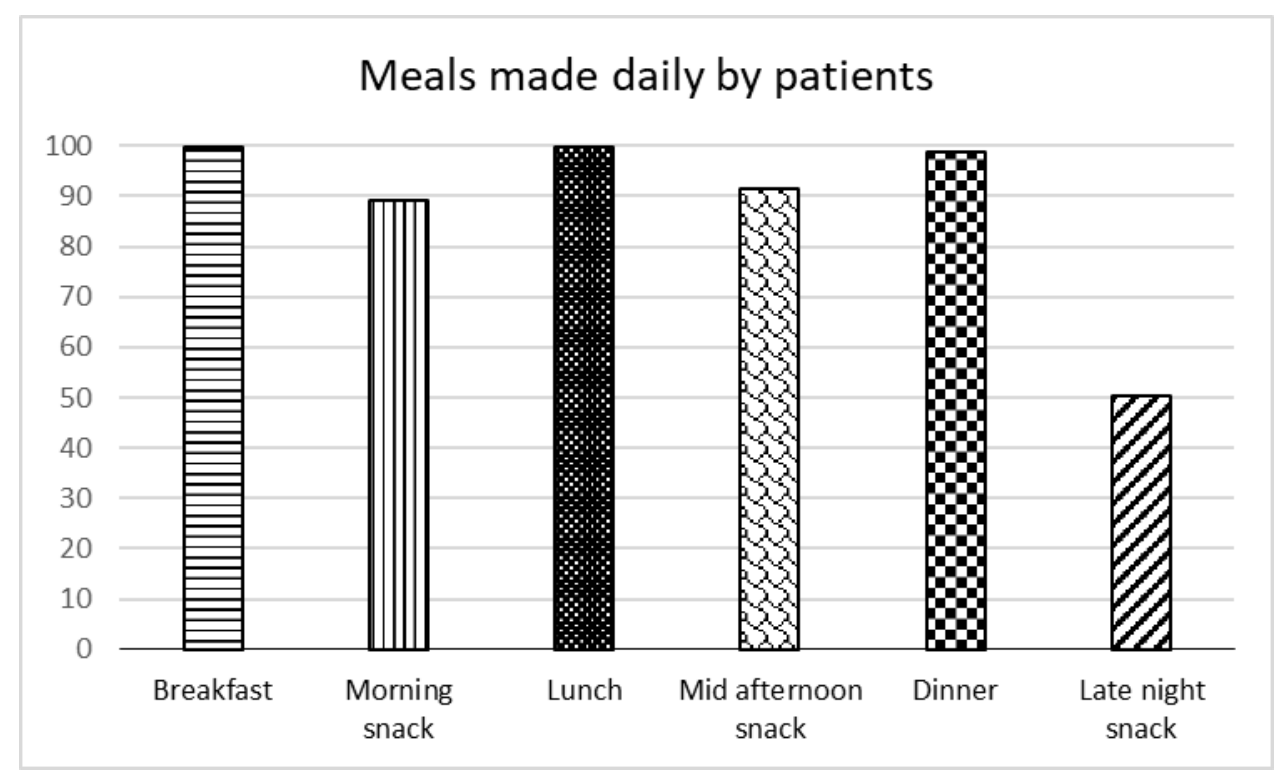

Figure 1: Compliance with recommended daily meals

In relation to the nutritional plan recommended in the "National Program" and the type of foods that patients included in their diet, the most relevant results showed that $84.1 \%$ and $70.1 \%$ of the patients complied with the food recommended for breakfast (milk and cereal) respectively. Among those who made the morning snack, $75.3 \%$ followed the recommendation to include in that meal dairy or fruits; while at lunch the degree of compliance with the three recommended foods was $93.9 \%$ for proteins, $72.0 \%$ for cereals and $84.1 \%$ for vegetables, with a very low compliance in fruit intake. The inclusion of the recommended components in the National Plan for "snacks" were heterogeneous (60.9\% incorporated milk; 39.1\% cereals; $23.2 \%$ dairy and $33.3 \%$ yogurt / fruits); and at dinner, only $37 \%$ met the recommendations to include vegetables. Finally, among those who complied with the night snack, $85.7 \%$ followed the guidelines of including a yogurt in this meal (Fig. 2). 


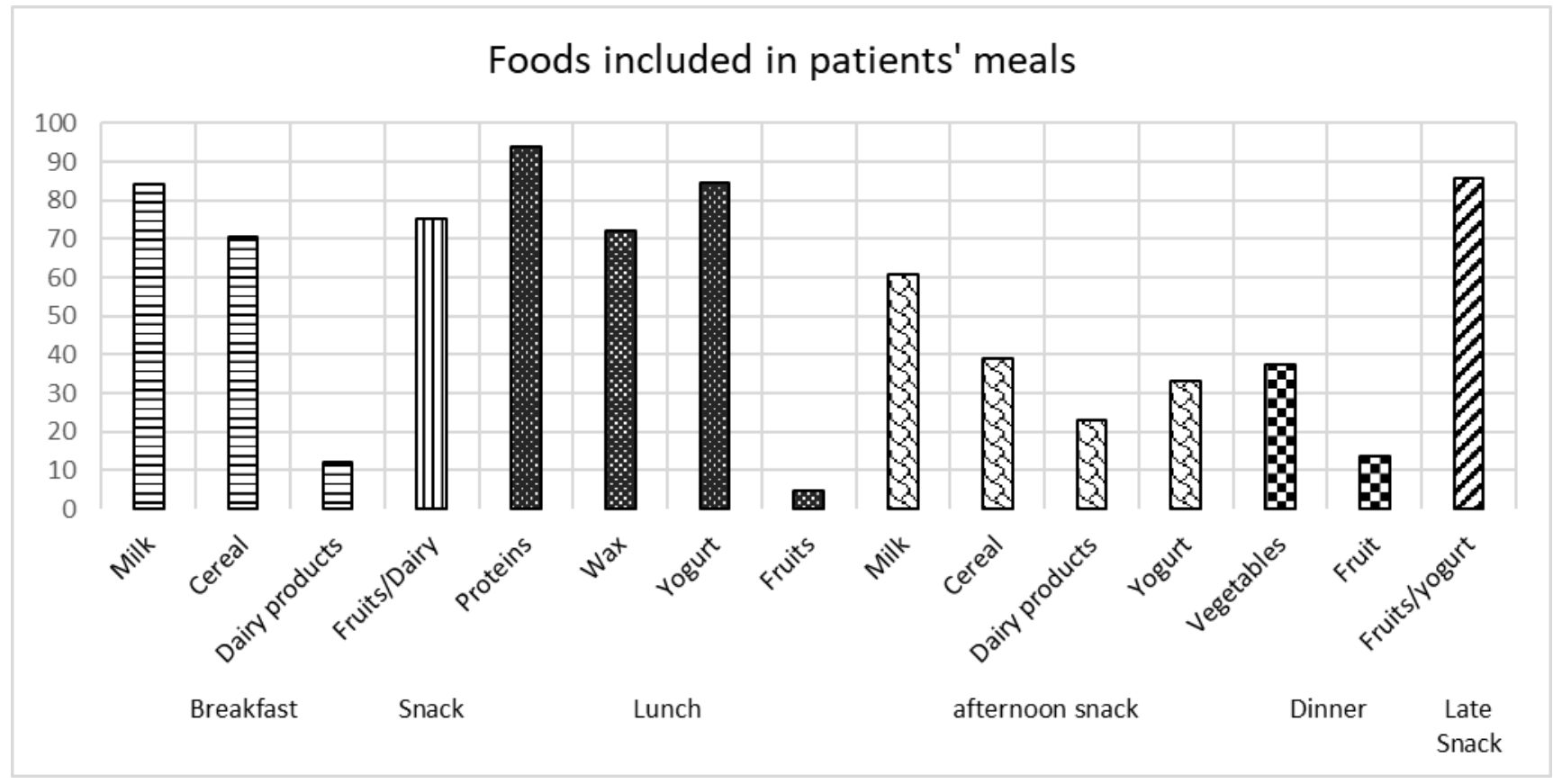

Figure 2: Type of food included in meals

The body mass index (BMI) of the surveyed patients, based on the data found in their clinical records, were grouped according to the values of "normal weight", "overweight" and "obesity". The results showed that $46.5 \%$ of the patients were obese, $38 \%$ were overweight, and only $15.5 \%$ had a normal weight range (Fig. 3).

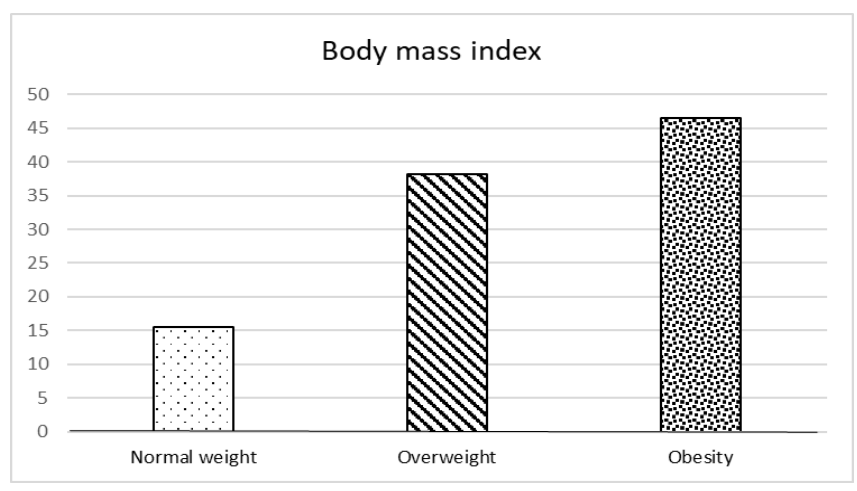

Figure 3: Body mass index data
The data related to the lipid profile of the patients under Diabetes Program were obtained though their clinical records and then grouped into cataloged values; for the cholesterol "desired", "high risk" and "high risk"; and for triglycerides levels "normal", "slightly increased", "high level" and "very high level"; according the recommended values for total cholesterol and triglycerides respectively.

Regarding total cholesterol level (TC), most of the patients $(60.5 \%)$ presented a desirable value (less than or equal to $200 \mathrm{mg} / \mathrm{dl}$ ), fulfilling one of the metabolic control objectives; while $29.6 \%$ of the patients presented an acceptable TC levels (between 200-239 mg/dl), and 9.9\% had unacceptable values of TC levels (more than $240 \mathrm{mg} / \mathrm{dl}$ ). In relation to triglycerides (TGC), the results indicated that $50 \%$ of the patients had a normal triglyceride levels (values lower than $150 \mathrm{mg} / \mathrm{dl}), 34.1 \%$ had acceptable levels between $150-199 \mathrm{mg} / \mathrm{dl}$, while $11 \%$ had elevated levels (values of 200 to $499 \mathrm{mg} / \mathrm{dl}$ ), while $4.9 \%$ presented values that exceeded $500 \mathrm{mg} / \mathrm{dl}$, showing a poor metabolic control (Fig. 4).

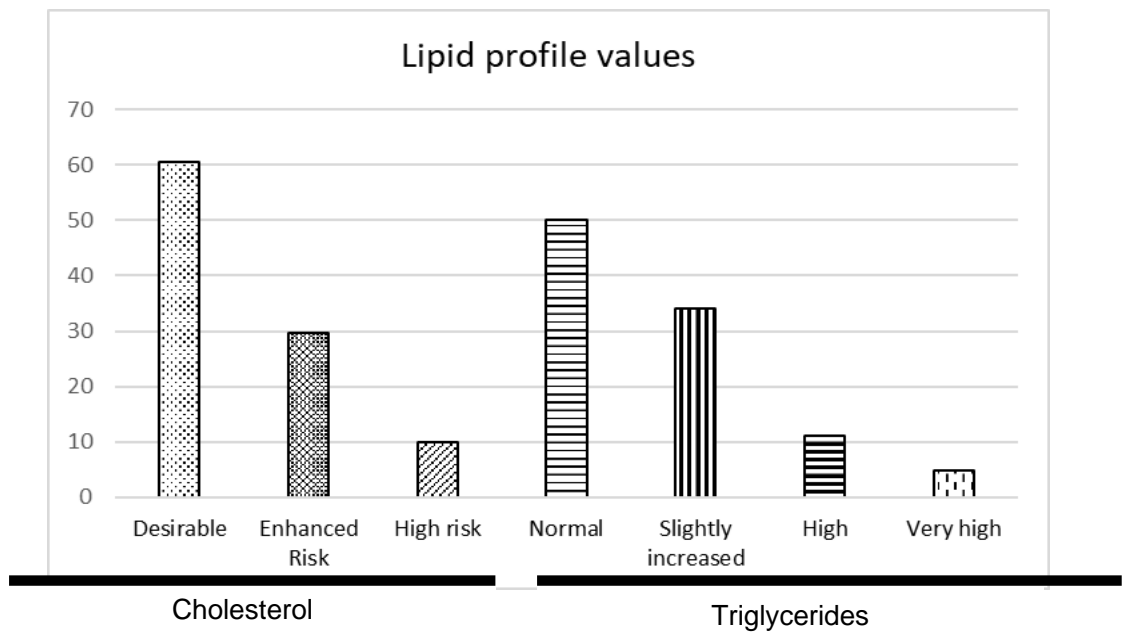

Figure 4: Lipid profile in patients enrolled in National Diabetes Program 
Regarding the lifestyle (alcohol consumption, smoking habit) and physical activity of the participants of the National Diabetes Program, the results indicated that the majority of the patients neither consumed alcoholic beverages (75.6\%), nor smoked (89\%); while only $68.3 \%$ of participants performed physical activity, although $75 \%$ of them this activity was irregularly or inadequately according to the guidelines established by the program (Fig. 5).

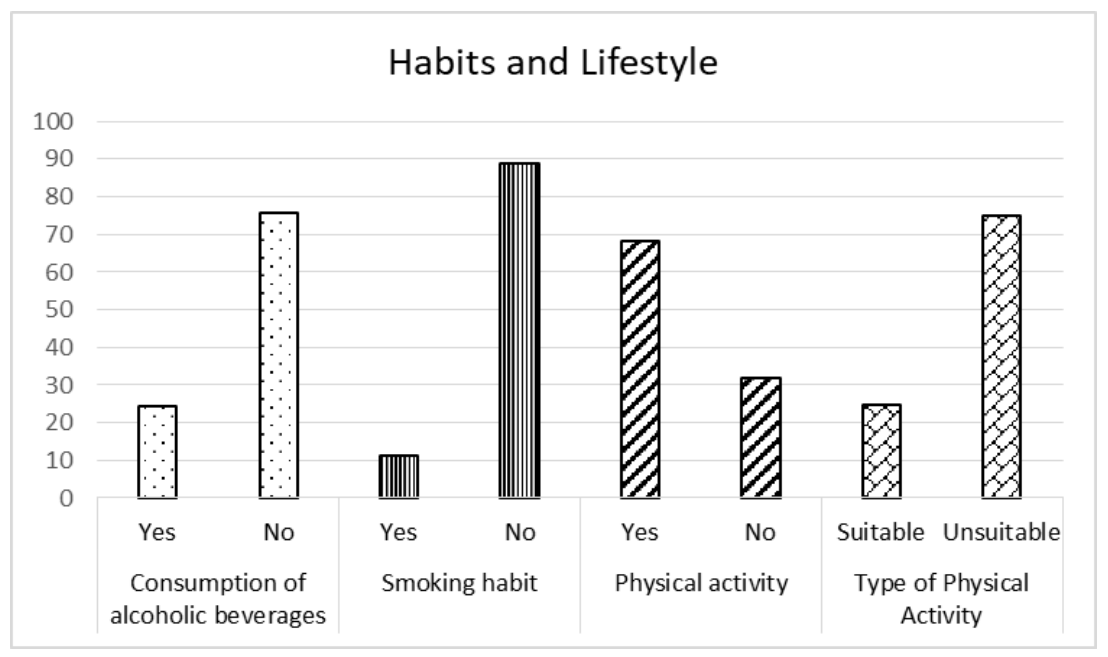

Figure 5: Characteristics of the Lifestyle and habits of the participants of the National Diabetes Program

Regarding the pharmacological treatment, $88.7 \%$ of the participants knew the name of the medicine they were using to treat their diabetes, while $73.5 \%$ of them knew the generic name of the drug. Failure in the continuity of the treatment was found in $48.1 \%$ of the patients.

About the type of medication provided by the Program, more than half of the patients received metformin, $34 \%$ received oral hypoglycemic agents, while a large part of the participants associated insulin with their oral treatments (Fig. 6). In those patients who received insulin, $81.7 \%$ admitted having received specific education for its use and application; however, only $62.9 \%$ of them demonstrated expertise in the application form at the time of the study evaluation.

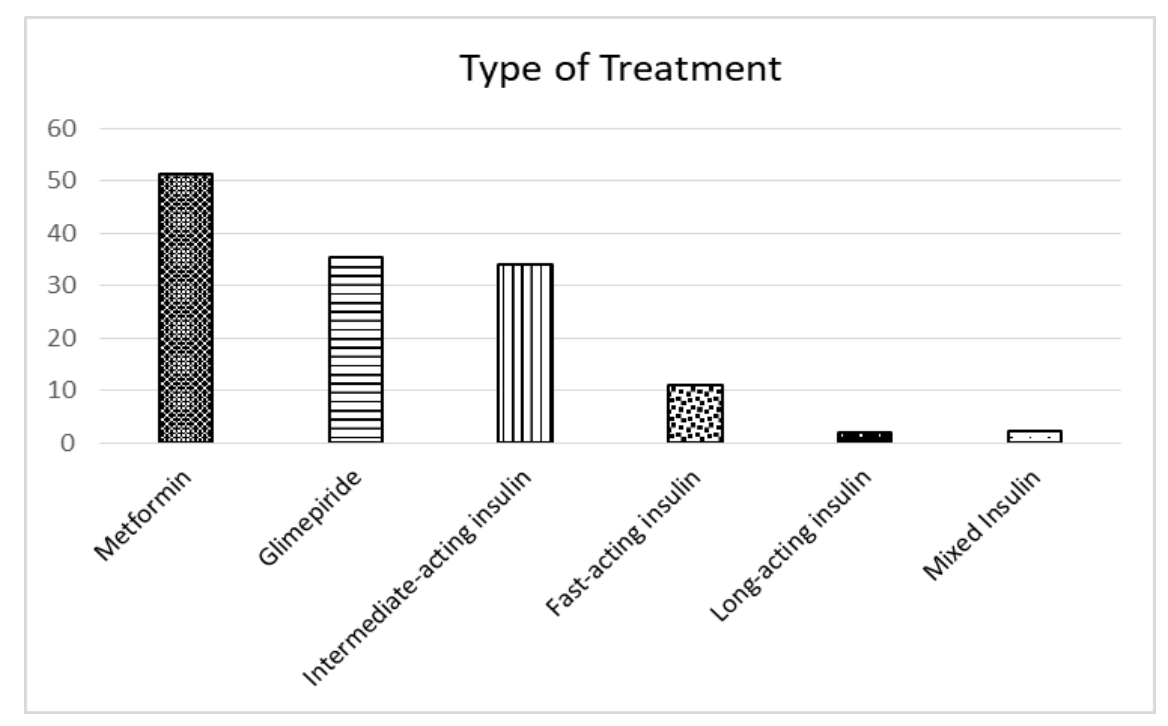

Figure 6: Type of pharmacological therapy received by participants of the National Diabetes Program

Patient's attendance to the educational workshops included in the Program was dissimilar. $51.2 \%$ of the patients attended to every educational activity proposed by the Program, while the other half of the respondents were divided between those who participated to almost all activities (7.5\%), those who never did so $(9.8 \%)$, those who attended only the first time (11.0\%) and those who participated occasionally $(20.7 \%)$.

The level of knowledge of the patients regarding the glycemic values, the guidelines to be follow according to those values, and the complications associated with the mismanagement of Diabetes was high in all cases $(85.4 \%$, $95.7 \%$ and $87.8 \%$ respectively).

To evaluate the evolution of the disease and the treatment accomplished in the last month, it was used the glycosylated hemoglobin test. $37.3 \%$ of the patients had normal levels of HbA1C (values less than or equal to $6.5 \%$ ); $33.3 \%$ registered acceptable control levels (HbA1C between 6.5 and 8\%), and $29.3 \%$ showed unacceptable levels (values higher than $8 \%$ ). 
Compliance with the periodical medical controls performance was verified in two ways: by a patient's interview and by checking in the clinical records the annual mandatory clinical test included in the National Diabetes Program (24-hour urine analysis and retinal exam). In these practices, there was a disparity of data between the once reported by patients and data recorded from medical record. $45.1 \%$ of the patients answered that they had performed retinal control in the last year period, while $74.4 \%$ of the patients self-reported that they performed urine test. However, when reviewing the personal medical records, it was found that only $22 \%$ of the patients did perform a retinal examination, and that $60 \%$ had carried out a 24 -hour urinalysis in the last year period.

The way of how diabetic patients performed their health care is associated to the severity of complications due to this chronic disease12. Diabetes control is associated to economic, environmental, political, and social conditions in which people live. Paraguay, as many countries in South America is considered low income country where the population affected by a disease like diabetes, depend directly entirely on the health policies of governments. Therefore, having national programs that meet these need is not only desirable but highly necessary. But it is not only important to have a Program but also to evaluate its effectiveness in terms of meeting the proposed guidelines and the disease control in order to ensure that the State's efforts bear fruit.

The National Diabetes Program of Paraguay is focused on five main pillars: establishing healthy eating habits; providing education for disease's understanding; promoting an adequate lifestyle and physical activities among patients; guarantee access to free medication treatment, and ensuring periodic medical control to avoid complications.

These aspects are scientifically validated as potential modifiers of the ominous course of diabetes over time ${ }^{13-16}$

Hence, adherence to these 5 proposals is well indicator of the program's success. However, according to results obtained in the study, it can be stand that most of the patients do not comply with many of National Diabetes Program guidelines.

Likewise, in relation to nourishment habits or physical activities, $75 \%$ of the patients did not accomplish the recommendations regarding the time and frequency of meals intake or the athletic workout.

The most important evidence of non-compliance of Program recommendations was reflected in the high number of overweight (38\%) and obese (46.5\%) patients.

Regarding the pharmacological treatment of type II Diabetes patients under the Program, although an acceptable adherence was evidenced, the insulin requirement in half of the patients indicates a therapeutic failure of oral treatments. This treatment failure is reflected in the fact that $62.7 \%$ of the individuals had sub-optimal HbA1C evaluation by laboratory analysis.

The lack of continuity in the medical controls and the low compliance of urine renal function test or retinal examination, threaten the early detection of complications such as retinopathy and nephropathy, which are indicators of a progression of the disease.

This study demonstrated that despite the governmental efforts embodied in the National Diabetes Program, the level of adherence of patients to the global treatment of diabetes was low in relation to the five therapeutic pillars proposed by the program (eating habits, style life/physical activities, education, drug treatment, and medical controls). It is imperative then that this type of health programs should nominalized and personalized the follow-up of each patient in order to guarantee the compliance to non-pharmacological and pharmacological treatments proposed by the program. Although this type of personalized follow-up may be laborious, the impact in terms of health benefits and in the reduction of disease complications will be surely rewarded in better health conditions of the diabetic population and in costs' reduction for the health system.

\section{REFERENCES}

1. Cho N.H., Shaw J.E., Karuranga S., Huang Y., Fernandes J.D.R., Ohlrogge A., Malanda B. IDF Diabetes Atlas: Global estimates of diabetes prevalence for 2017 and projections for 2045. Diabetes Res. Clin. Pract. 2018; 138:271-281.

2. Association A.D. Classification and diagnosis of diabetes: Standards of medical care in Diabetes. Diabetes Care. 2018; 41:13-27.

3. Ganasegeran K, Hor CP, Jamil MFA, et al. A Systematic Review of the Economic Burden of Type 2 Diabetes in Malaysia. Int J Environ Res Public Health. 2020; 17(16):5723.

4. Hu F.B. Sedentary lifestyle and risk of obesity and type 2 diabetes. Lipids. 2003; 38:103-108. doi: 10.1007/s11745-0031038-4.

5. Wu Y., Ding Y., Tanaka Y., Zhang W. Risk factors contributing to type 2 diabetes and recent advances in the treatment and prevention. Int. J. Med Sci. 2014;11: 1185-1200.

6. McCarthy M.I. Genomics, Type 2 Diabetes, and Obesity. N. Engl. J. Med. 2010; 363:2339-2350.

7. Wing R.R., Bolin P., Brancati F.L., Bray G.A., Clark J.M., et al Cardiovascular effects of intensive lifestyle intervention in type 2 diabetes. N Engl J Med 2013; 369:145-154.

8. Marin GH, Risso P, Sbatella D, Haag G. Treatment adherence by personalizing the drug dispensing for diabetic patients in social vulnerable situation. Quality in Primary Care (2015)23(2):9396.

9. Maciel O, Vera Z; Marin GH; Maidana M; Samaniego L, et al. CostEffectiveness of drug compliance in type 2 diabetes mellitus patients; B. M. Vrushabendra Swamy; Research Journal of Pharmaceutical, Biological and Chemical Sciences; 2018; 9(5) 1824-1829.

10. World Health Organization: Definition, Diagnosis and Classification of Diabetes Mellitus and its Complications: Report of a WHO Consultation. Part 1: Diagnosis and Classification of Diabetes Mellitus. Geneva, World Health Org., 1999.

11. Ministry of Health \& Social Welfare, Paraguay. National Program of Diabetes. 2020. Available in: http://www.mspbs.gov.py/diabetes/index.php?option=com_co ntent\& view=article\&id . Last access: 18 December, 2020.

12. Hill-Briggs F, Adler N, Berkowitz S, Chin M., Gary-Webb T, NavasAcien A, Thornton P, Haire-Joshu D. Social Determinants of Health and Diabetes: A Scientific Review. Diabetes Care Jan 2021; 44 (1):258-279.

13. Diabetes Prevention Program Research Group Long-term effects of lifestyle intervention or metformin on diabetes development and microvascular complications over 15-year follow-up: the Diabetes Prevention Program Outcomes Study Lancet Diabetes Endocrinol, 2015; 3:866-875

14. Ajala O., English P. Pinkney J. Systematic review and metaanalysis of different dietary approaches to the management of type 2 diabetes. Am J Clin Nutr, 2013; 97:505-516

15. M.E. Lean, W.S. Leslie, A.C. Barnes, N. Brosnahan, G. Thorn, L. Mc Combie, et al. Primary care-led weight management for remission of type 2 diabetes (DiRECT): an open-label, clusterrandomised trial Lancet, 2017; 391:541-551

16. Wing R.R., Bolin P., Brancati F.L., Bray G.A., Clark J.M. , et al. Cardiovascular effects of intensive lifestyle intervention in type 2 diabetes N Engl J Med 2013; 369:145-154 